\title{
Gastric Conduit Perforation: A Late Fatal Complication after Esophagectomy
}

\author{
Aditya A. Kulkarni ${ }^{1}$, Vivek Chauhan ${ }^{1}$, Vishal Sharma ${ }^{2}$, Harjeet Singh ${ }^{1}$ \\ 1. Department of General Surgery, Postgraduate Institute of Medical Education and Research (PGIMER), Chandigarh, \\ IND 2. Department of Gastroenterology, Postgraduate Institute of Medical Education and Research (PGIMER), \\ Chandigarh, IND
}

Corresponding author: Harjeet Singh, harjeetsingh1982@gmail.com

\begin{abstract}
With an increasing number of long-term survivors of carcinoma esophagus, it is important to be vigilant about postoperative complications related to gastric tubes. Perforation of the gastric conduit has been rarely seen, with very few case reports in the literature. We report a rare case of perforation of the gastric tube conduit in a patient who had previously undergone esophagectomy for squamous cell carcinoma of esophagus five years ago. The patient presented with diffuse peritonitis in an emergency. On exploration, a large perforation was present on the anterior wall of the gastric conduit. This was closed with primary suture repair. Histopathology revealed nonspecific inflammatory changes. Unfortunately, the patient succumbed to severe sepsis and multiorgan dysfunction despite early surgical intervention and critical care management. Conduit perforation can be a major source of morbidity and mortality. Although gastric conduit is predisposed to ulcer formation due to multiple reasons, conduit perforation may occur only in rare cases. We recommend that surveillance endoscopy for conduit ulcer should be performed in long-term survivors after esophagectomy. Patients with conduit ulcers would benefit from long-term acid suppression with protonpump inhibitors.
\end{abstract}

Categories: Gastroenterology, General Surgery, Oncology

Keywords: surgery, emergency, cancer, infection, esophagus

\section{Introduction}

In recent years, there has been an improvement in the prognosis of patients with carcinoma esophagus. Five-year overall survival rates are reported to be as high as $30 \%$ to $40 \%$ in patients who undergo resection [1]. Surgical resection i.e esophagectomy is the treatment of choice for patients who present with resectable disease. Reconstruction following esophagectomy can be done in a number of ways (gastric, colonic or jejunal conduits). The vast majority of reconstructions after resection for esophageal cancer are performed with the tubularized stomach as a conduit [1]. With better survival of these patients, complications related to the gastric tube, such as ulcer formation, may be seen. Perforation of a gastric tube ulcer is a rare and catastrophic complication. Here, we report a case of gastric tube ulcer perforation into the peritoneal cavity five years after esophagectomy for carcinoma esophagus.

Received 06/17/2019

Review began 06/17/2019

Review ended 06/18/2019

Published 06/24/2019

๑) Copyright 2019

Kulkarni et al. This is an open access article distributed under the terms of the Creative Commons Attribution License CC-BY 3.0., which permits unrestricted use, distribution, and reproduction in any medium, provided the original author and source are credited.

\section{Case Presentation}

A 62 -year-old man presented to the emergency surgery outpatient department with complaints of acute severe abdominal pain for the past two days. Physical examination was remarkable for tachycardia, hypotension, and marked abdominal guarding and rigidity. He had a past history of squamous cell carcinoma of the lower thoracic esophagus, for which the patient underwent transhiatal esophagectomy with orthotopic gastric tube conduit five years ago. The patient was a chronic smoker for many years, and also gave a history of occasional alcohol use. Laboratory studies revealed leucocytosis (white cell count 13,500), severe metabolic acidosis ( $\mathrm{pH}=7.19)$ and deranged renal parameters with severe hyperkalemia (Sodium-133 meq/L, Potassium-5.8 meq/L, Urea-138 mg/dL, Creatinine $4.12 \mathrm{mg} / \mathrm{dL}$ ).

Ultrasound of the abdomen showed gross ascites with multiple septations. Erect X-ray abdomen revealed free air under the diaphragm, confirming the diagnosis of perforation peritonitis. The patient was resuscitated with intravenous fluids and antibiotics. Emergency dialysis was performed in view of refractory hyperkalemia and severe metabolic acidosis. Bilateral flank drains were inserted with a view to draining out the infected fluid in order to attain partial source control. These drained around $1000 \mathrm{ml}$ of foul smelling greenish fluid.

He responded favorably to initial resuscitation and was taken up for emergency surgery. At laparotomy, there was gross intraperitoneal contamination with biliopurulent fluid. There were dense inter-bowel and parietal adhesions. After extensive adhesiolysis, a large perforation measuring $3 \mathrm{~cm}$ by $3 \mathrm{~cm}$ was found on the anterior aspect of the distal part of the gastric tube conduit, approximately $2 \mathrm{~cm}$ proximal to the pylorus [Figure $1 a$ and $1 \mathrm{~b}$ ]. The perforation site was immediately below the right crus, which was partially covering the perforation site. The edges were edematous and friable. After thorough peritoneal toileting, the 


\section{Cureus}

perforation was closed primarily after freshening the margins [Figure 1c]. Witzel-type feeding jejunostomy was placed to ensure enteral nutrition in the postoperative period. Postoperatively, he remained intubated and on inotropic support in view of severe sepsis and shock. Dialysis was repeated on postoperative day one. However, he failed to respond to supportive management and succumbed to his illness on postoperative day two. Histopathologic examination of biopsy from perforation edge revealed non-specific inflammation.

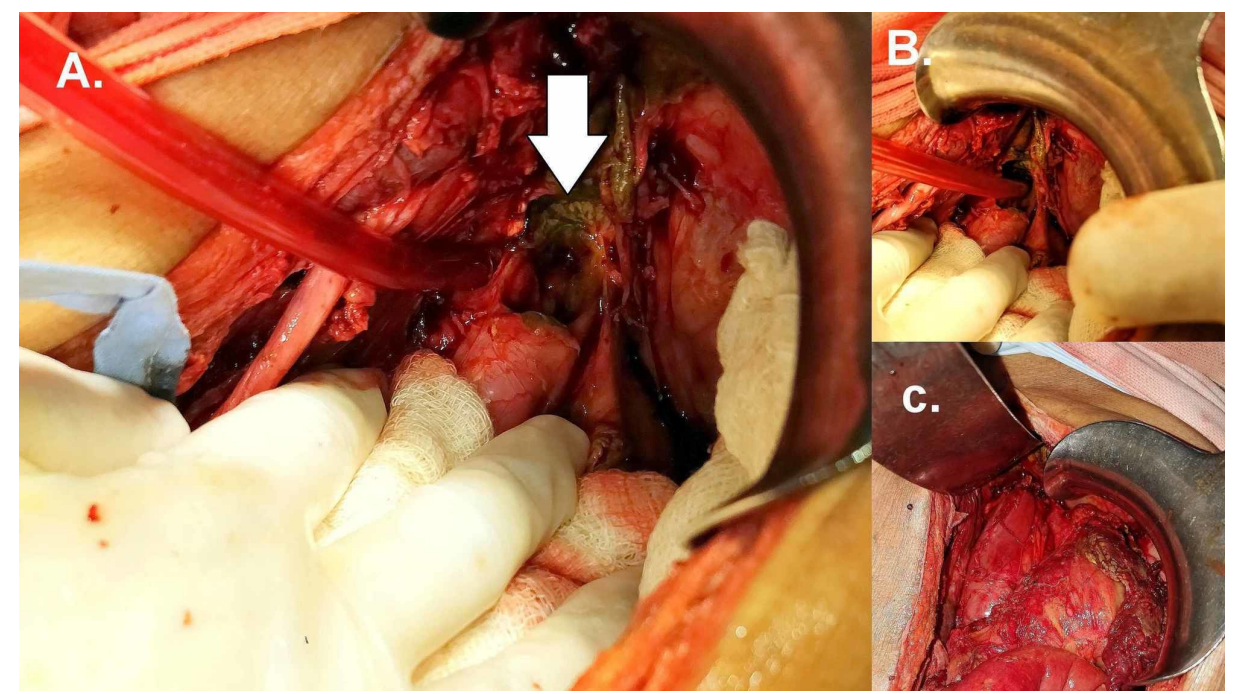

\section{FIGURE 1: Operative photograph}

$1 \mathrm{~A}$ and $1 \mathrm{~B}$. Perforation of the gastric tube seen at the hiatus (1C). After primary repair of the perforation.

\section{Discussion}

Tubularized stomach conduit with cervical esophagogastric anastomosis is the commonest method of reconstruction after esophagectomy for esophageal carcinoma [1]. Motoyama et al. in a prospective study reported a $47 \%$ prevalence of secondary gastric tube disorders [2]. Prevalence of ulcer formation in the gastric tube ranges from $6.1 \%-19.4 \%$ [2-4]. Although ulcer formation is common, perforation of a gastric tube ulcer is a very rare complication, with one review revealing only thirteen cases in the English literature [5].

Various causes and mechanisms of gastric tube ulceration have been proposed. Acid production in the gastric tube is expected to be low considering the loss of acid-secreting mucosa and vagotomy as a part of the surgical procedure. However, gastric acid secretion recovers with time and can return to normal [6-7]. This may predispose to ulcer formation. Blood supply to the gastric tube, especially in the proximal lesser curve is tenuous. Hence ulcer formation is common in this location [5]. However, the perforation in our case was in the prepyloric region, which raises the possibility of other causative factors. Excessive regurgitation of alkaline duodenal contents is injurious to the gastric mucosa and may promote ulceration and impair ulcer healing, especially with posterior mediastinal reconstruction like in our case [8]. Tumour recurrence, radiation, use of non-steroidal anti-inflammatory drugs and gastric stasis secondary to denervation are other putative causes.

Route of reconstruction may play a part in predisposing to ulcer formation. Aiko et al. reported an increased incidence of peptic ulcers in the gastric tube reconstructed via the retrosternal route as compared to the posterior mediastinal route [9]. The average duration from esophagectomy to ulcer perforation has been reported as three years and four months [5], but cases have been reported as late as 12.5 years after surgery [10]. Mortality after perforation of tube ulcer is reported to be as high as $84.6 \%$ [5]. Conduit ulcer may perforate into various locations like aorta, trachea, bronchus, thoracic cavity, pericardium or sternum $[5,11]$. However, our case was different in that there was free perforation into the peritoneal cavity. To the best of our knowledge and literature review, this is the first report of such complication after esophagectomy. Due to the rarity of this complication, it is difficult to suggest an ideal approach to its management.

Laparotomy with either primary repair or omental patch closure is the best possible option in a patient with peritonitis, as in the index case. A high index of suspicion and early diagnosis and treatment are critical to ensure a successful outcome. It is especially important to be vigilant about surveillance and treatment of gastric tube ulcers, given the significant incidence of ulceration and high mortality after perforation. More than $50 \%$ of gastric tube ulcers do not cause pain, possibly as a result of vagotomy [12]. Hence, a surveillance program may be warranted in post-esophagectomy patients, especially those at risk (smoker, NSAID user). In patients who are detected to have conduit ulcers, detection, and treatment of Helicobacter pylori and acid suppression with proton pump inhibitors may be done, to minimize the chance of ulcer 
complication.

\section{Conclusions}

This case illustrates a rare and unprecedented scenario of intraperitoneal perforation of a gastric conduit ulcer. This is a serious complication with high morbidity and mortality. Gastric conduit is prone to develop ulcers for various reasons. Periodic endoscopic surveillance of the conduit for ulcers and early detection and treatment of $H$. pylori is essential to prevent this complication.

\section{Additional Information \\ Disclosures}

Human subjects: Consent was obtained by all participants in this study. Conflicts of interest: In compliance with the ICMJE uniform disclosure form, all authors declare the following: Payment/services info: All authors have declared that no financial support was received from any organization for the submitted work. Financial relationships: All authors have declared that they have no financial relationships at present or within the previous three years with any organizations that might have an interest in the submitted work. Other relationships: All authors have declared that there are no other relationships or activities that could appear to have influenced the submitted work.

\section{References}

1. Orringer MB, Marshall B, Chang AC, et al.: Two thousand transhiatal esophagectomies: changing trends, lessons learned. Ann Surg. 2007, 246:363-374. 10.1097/SLA.0b013e31814697f2

2. Motoyama S, Saito R, Kitamura M, et al.: Prospective endoscopic follow-up results of reconstructed gastric tube. Hepatogastroenterology. 2003, 50:666-9.

3. Maier A, Tomaselli F, Sankin O, et al.: Acid-related diseases following retrosternal stomach interposition . Hepatogastroenterology. 2001, 48:899-902.

4. Wang LS, Huang MH, Huang BS, Chien KY: Gastric substitution for resectable carcinoma of the esophagus: an analysis of 368 cases. Ann Thorac Surg. 1992, 53:289-94.

5. Ubukata H, Nakachi T, Tabuchi T, et al.: Gastric tube perforation after esophagectomy for esophageal cancer. Surg Today. 2011, 41:612-9. 10.1007/s00595-010-4476-9

6. Gutschow C, Collard JM, Romagnoli R, Salizzoni M, Holscher A: Denervated stomach as an esophageal substitute recovers intraluminal acidity with time. Ann Surg. 2001, 233:509-14. 10.1097/00000658200104000-00005

7. Okada N, Nishimura O, Sakurai T, Tsuchihashi S, Juhri M: Gastric functions in patients with the intrathoracic stomach after esophageal surgery. Ann Surg. 1986, 204:114-21.

8. Katsoulis IE, Robotis I, Kouraklis G, Yannopoulos P: Duodenogastric reflux after esophagectomy and gastric pull-up: the effect of the route of reconstruction. World J Surg. 2005, 29:174-81. 10.1007/s00268-004-75680

9. Aiko S, Ando N, Shinozawa Y, et al.: Increased chemiluminescence and ulcer development in the low blood flow state of the gastric tube for esophageal replacement. J Clin Gastroenterol. 1993, 1:161-6.

10. Hanashi T, Ide H, Nogami A, et al.: A case report on the perforation of a gastric tube ulcer after esophageal reconstruction for cancer [article in Japanese]. Nihon Kyobu Geka Gakkai Zasshi. 1991, 39:1242-6.

11. Patil N, Kaushal A, Jain A, et al.: Gastric conduit perforation. World J Clin Cases. 2014, 2:398-401. Accessed: June 24, 2019: 10.12998/wjcc.v2.i8.398

12. Texter EC, Jr: Ulcer pain mechanisms. The clinical features of active peptic ulcer disease and implications for therapy. Scand J Gastroenterol Supplement. 1987, 134:1-20. 